\title{
A literature review on Building Integrated Solar Energy Systems (BI-SES) for façades - photovoltaic, thermal and hybrid systems
}

\author{
Karol Bot ${ }^{1, *}$ (D), Laura Aelenei ${ }^{1}$, Maria da Glória Gomes ${ }^{2}$ (D), and Carlos Santos Silva ${ }^{3}$ \\ ${ }^{1}$ Laboratório Nacional de Energia e Geologia (LNEG), 1649-038 Lisbon, Portugal \\ ${ }^{2}$ CERIS, Department of Civil Engineering, Architecture and Georesources (DECivil), Instituto Superior Técnico, Universidade \\ de Lisboa, 1049-001 Lisbon, Portugal \\ ${ }^{3} \mathrm{IN}+$, Center for Innovation, Technology and Policy Research /LARSyS, Department of Mechanical Engineering (DEM), \\ Instituto Superior Técnico, Universidade de Lisboa, 1049-001 Lisbon, Portugal
}

Received: 9 August 2021 / Received in final form: 11 November 2021 / Accepted: 11 November 2021

\begin{abstract}
The building façade has a crucial role in acting as the interface between the environment and the indoor ambient, and from an engineering and architecture perspective, in the last years, there has been a growing focus on the strategic development of building façades. In this sense, this work aims to present a literature review for the Building Integrated Solar Energy Systems (BI-SES) for façades, subdivided into three categories: thermal, photovoltaic and hybrid (both thermal and photovoltaic). The methodology used corresponds to a systematic review method. A sample of 75 works was reviewed (16 works on thermal BI-SES, 37 works on photovoltaic BI-SES, 22 works on hybrid BI-SES). This article summarises the works and later classifies them according to the type of study (numerical or experimental), simulation tool, parametric analysis and performance when applied.
\end{abstract}

\section{Introduction}

In order to overcome the substantial challenges faced by building sector in European Commission, being responsible for approximately $40 \%$ of the energy consumption and $36 \%$ of the greenhouse gas emissions, the scientific community together with policy makers are continuously working on delivering and adopting innovative solutions, advanced practices and regulations, respectively. In recent years, building regulations have gradually introduced new requirements to ensure a phased decarbonization of building sector and an increasing of its energy performance. In 2010, the Energy Performance of Buildings Directive (EPBD) recast [1] introduced requirements with the objective of attaining environmental and energy efficiency goals adopting the nearly Zero Energy Buildings (nZEB) Performance for new and existing buildings. A special attention was given to the public building sectors in terms of energy efficiency measures, drivers and barriers [2] and their optimal calculation [3].

\footnotetext{
* e-mail: karolbot@live.com
}

For a building to be considered nZEB, it must reduce its energy consumption and generate energy from renewable sources, which can compensate for the majority of the building's consumption assuring at the same time thermal comfort. Taking into account the specific requirements and specifications for nZEB performance, a special attention has been paid to the integration of renewable systems in the buildings footprint or nearby. At building level these renewable technologies are mostly integrated in the building envelope (walls and roofs).

Usually, the building façade has a crucial role in performing as the interface between the environment and the indoor ambient. With the integration of renewable energy (especially solar), the buildinǵs facade has a significant impact on the occupant's comfort, building energy demands, and the aesthetics of the building. Commonly, designing a building façade takes into consideration several factors, as the climatic conditions and surrounding structures, indoor and spatial characteristics, needs of the building occupants regarding comfort and costs, among others. From an engineering and architecture perspective, in the last years, there has been a growing focus on the strategic development of building façades, it is, to contribute to meet the requirements of the high-performance regulations while being sustainable and 


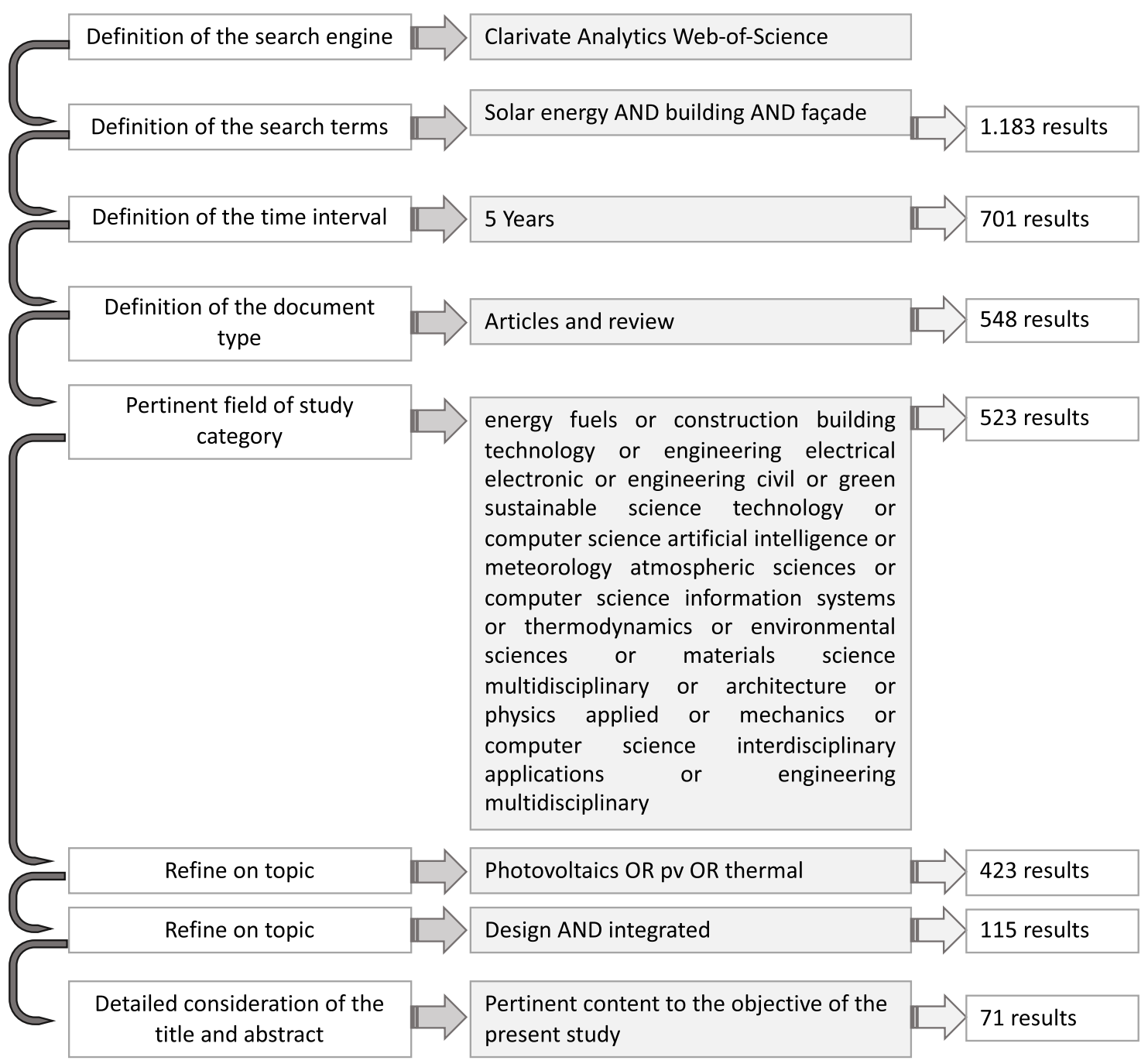

Fig. 1. State of the art survey method and results.

aesthetically pleasant. This strategic development brings new experiments, innovative systems, and technology to be integrated into the formal functions of the envelope [4].

The façade elements may improve the energy flexibility of the building by the adequation of the constructive elements thermal performance to climate and building usage profile, also by being adaptive or automated to adapt to the different boundary conditions. Given this context and the flexibility that façade elements can offer in the design process, innovative façade elements based on solar energy systems can significantly reduce the building energy demand [5].

Entire buildings are broad, multi-scale, multi-material, with exceptionally unique analysis approach frameworks with vast influences. When addressing the design, applications and control of Building Integrated Photovoltaic System (BIPV) and its relationship with the building itself, it becomes very complex to create functional systems that are adaptable and generally relevant to the improvement of energy performance; once there must be a trade-off between factors as life-cycle assessment and real improvement it brings to the energy demand reduction [6].
The present article provides a concise review of a sample of studies concerning Building Integrated Solar Energy Systems integrated into façades published in the last five years. This article presents the main scope of the works, a comparison of the outcomes through a table classification, and a discussion about trends in the field.

\section{Review methodology}

The present study presents a systematic review concerning innovative systems on façade BI-SES. The source of information used to acquire the data is the Clarivate Analytics Web-of-Science. Figure 1 presents in detail the survey method and rationale used for the systematic review. In summary, the eligibility criteria and study selection are based on the published material within the search terms, period, the relevance, keywords and abstract pertinent to the objectives, and consideration through the screening of appropriate content throughout the text. Thus, Figure 1 also presents the results regarding the number of publications filtered through the adopted survey 


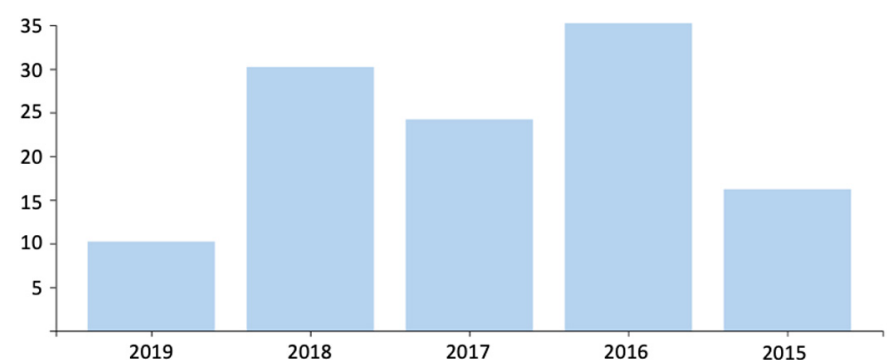

Fig. 2. Segmentation by year of publication.

methodology. The data items, summary measures and report characteristics are based on the study details (reference), study characteristics (study type and technology type), extension of analysis, among others.

In the survey step previous to the detailed consideration of the title and abstract pertinent to the objective of the study (resulting in 115 articles), the results obtained by the source of information were segmented concerning the year of publication (Fig. 2), journal of publication (Fig. 3) and country of submission (Fig. 4).

The remaining 75 articles were later segmented in the three mentioned categories: thermal, photovoltaic and hybrid BI-SES. The results are then presented in terms of summary of the manuscripts, and classification concerning the detailed system type, study type (experimental and/or numerical), simulation tool or technique, parameters under study in case of existence of a parametric analysis, and performance of the system considering its thermal, electrical and total efficieny.

\section{Results and discussion}

The obtained results were segmented into three categories: integrated solar thermal systems, integrated photovoltaic systems and integrated hybrid systems (both thermal and photovoltaic). The thermal system converts the solar radiation into thermal energy, the photovoltaic converts it into electricity and the hybrid converts both in electricity and thermal energy. The results presented here are described concerning their core information and are further classified in a table to compare the different studies.

\subsection{Integrated solar thermal systems}

A sample of 16 scientific articles was considered representative innovative solar thermal systems pertinent, among the 75 articles reviewed. A summary of the most pertinent is presented here, followed by a table summarising the studies.

In Prieto et al. [7], there is a detailed review concerning the possibilities of using solar cooling integrated façades by exploring their feasibility concerning orientation, efficiency, and climate in which it is used. It is concluded that warm-dry climates and east/west orientations are the best situations for solar cooling façade applications, reaching a theoretical solar fraction of $100 \%$ [7]. In Maurer et al. [8], a review is done

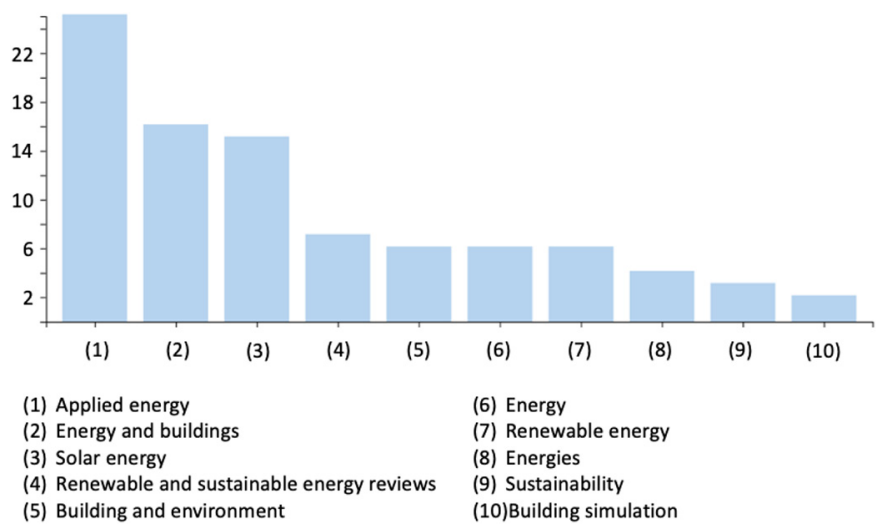

Fig. 3. Segmentation by the journal of publication.

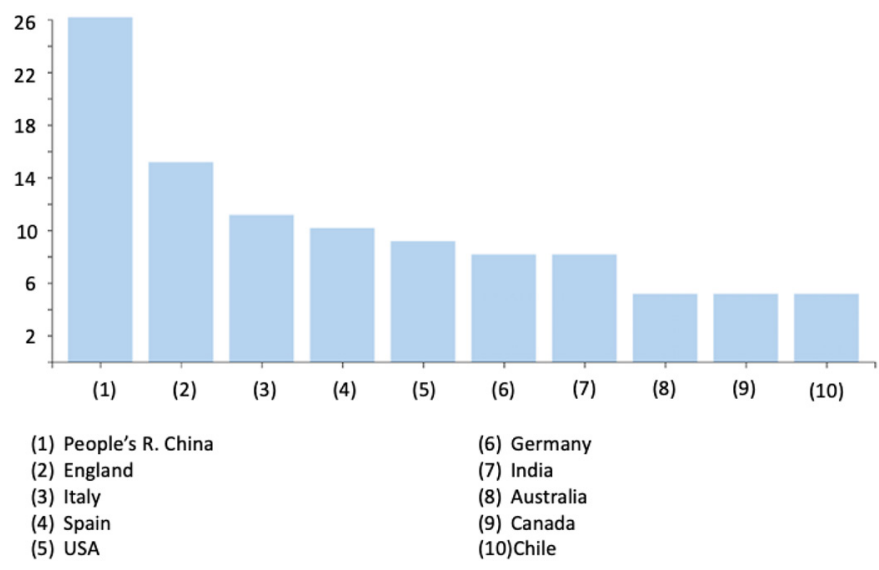

Fig. 4. Segmentation by country of submission.

on the most important contributions of recent years of building-integrated solar thermal systems, in terms of systems being designed, results being achieved in terms of thermal characterization, and simple models to evaluate the systems - being this publication an interesting compilation of studies to have an overall view of the current technology status for building integration. Valladares-Rendon et al. [9] developed a review of shading thermal solutions to decrease direct solar gains and improve energy savings, balanced with visual comfort. This publication emphasizes the importance of employing the solar thermal elements with more than one purpose in a single element, reinforcing that solar façade elements shall not have a static goal.

Velasco et al. [10], a Venetian blind double-skin façade with the integrated solar thermal collector is analysed through CFD software. The authors emphasize that the system would promote energy efficiency through avoiding direct solar gains while being aesthetically pleasant. In Sun et al. [11], the authors present a façade system with parallel transparent plastic slats sandwiched between glass panes to form a parallel slat transparent insulation material to reduce coupled convective and radiative heat transfer inside the air cavity of the panes of a double glazed window. 
It contributes to increasing the thermal resistance without constraining the daylight access to the point of visual comfort reduction. In $\mathrm{Li}$ et al. [12], the work focuses on the innovation of building-integrated solar thermal shading systems to reduce the energy demand and improve the daylight levels through modelling and simulations.

In O'Hegarty et al. [13], the authors review and analyse solar thermal façades in terms of the type, technology used, and the materials that constitute it. Daily efficiency models are presented based on a combination of analysis methods, comprising a good data resource for comparison among technologies. Lamnatou et al. [14] give a critical review of building-integrated solar thermal systems' simulation methods and usage. Not only thermal but other types of BI solar configurations such as photovoltaic and hybrid systems are covered.

In Buonomano et al. [15], the design and the thermodynamic analysis of a new prototype of a flatplate water-based solar thermal collector are developed, to integrate the system in building façades. The innovation is based on inexpensive materials and simplified design, aiming to reduce production and installation costs to improve market penetration. The applications are the production of hot water for domestic uses and space thermal comfort. This study contrasts with academia's tendency to develop expensive prototypes, as it aims to reach buildings in a faster manner by implications and technology transfer. As in the previously mentioned work, in Agathokleous et al. [16], it is also possible to find a flatplate based thermal collector integrated into building façade envelopes but based on using air as the fluid. The authors also focused on the use of cost-effective materials and simple design solutions. They developed an energy dynamic simulation model and economic performance analyses and concluded that the system payback would be close to six years.

In Garnier et al. [17], a novel incorporated solar collector with storage for water heaters was created, followed by a praiseworthy CFD investigation. The proposed project is composed of a heating component to give household independence through the high-temperature water system and considers the coordination of the system and the rooftop configuration, enabling the system unit to be inserted inside an auxiliary protected material board framework. In Resch-Fauster et al. [18], the proposition focuses on an integrated solar thermal collector and latent heat storage modules. The overheating protection supplied by this system has high efficiency of the optimized configuration, calculated in function of other thermophysical characteristics. This study also reinforces the modularity that the BI-SES systems have been adopting in recent years. In Ibanez-Puy et al. [19], a ventilated active thermoelectric envelope component is studied. It focuses on a modular active ventilated façade prototype with a thermoelectric system to be installed in the building envelope and provide a high comfort level. The system integrates a passive design strategy through the ventilation and an active strategy through an active thermoelectric solution. This study is an example of coupling passive and active techniques to improve the overall system performance.
In Guarino et al. [20], the authors study the performance of a building-integrated thermal storage system, intending to improve the energy performances of the system in a cold climate. Navarro et al. [21] presented a novel phase change material (PCM) system inside the structural horizontal building component. The structural element was a composed concrete with micro-encapsulated PCM located into 14 channels, coupled to a solar air collector to melt and induce the phase change. The technique presented by these authors may be considered more intrusive once coupled with hard materials of civil construction (concrete), which per si deliver a reliable structural performance throughout the whole building lifetime. In Hengstberger et al. [22], a solution is presented by using PCM embedded into the absorber insulation which buffers the heat during the day and releases it at night. A parametric analysis is developed using a dynamic simulation tool to find the best melting temperature of a thin layer of PCM at different positions.

In Shen et al. [23], the authors introduce an innovative compact solar thin film with an interiorly extruded pin-fin flow channel convenient for building integration. A simulation model was used, and a prototype of the solar thin film was fabricated to test the system under different controlled conditions. The methodology presented by this work is pertinent once it discusses the process of designing and testing. In $\mathrm{He}$ et al. [24], an innovative tile-shaped dual-function solar collector is analysed for water heating. The study is developed using CFD software and aims not only to provide optimal designs but also to meet pleasing aesthetics. In Giovanardi et al. [25], a modular unglazed solar thermal façade system was developed to aid the installation of active solar façades, with a particular focus on the renovation of existing buildings. In He et al. [26], the authors investigate the loop-heat-pipe water heating performance of an innovative heat pump assisted solar, using theoretical and experimental methods.

Table 1 presents the complete list and classification of the solar thermal systems reviewed in this work, considering the system type, existence/non-existence of experimental and numerical analysis, existence/non-existence of parametrical analysis and details, reached efficiency of the system under study. The terminology (N.S.) stands for "not stated", meaning that the article did not mention the feature.

The results obtained show that there is no specific trend concerning the systems under study in the most recent publications concerning the solar thermal systems. However, the focus can be given to the integration between passive and active techniques and the modularity and multiple purposes of the same element. The technologies vary from innovative system design to innovative methods of operation or material combination. Also, the thermal efficiency $\left(\eta_{t}\right)$ of the systems is, in most cases, not directly assessed. Most of the studies using dynamic simulation evaluated the impact of the systems in thermal behaviour by calculating nominal energy needs for heating and cooling of the thermal zone, based on determined setpoints. Others use computational fluid dynamics analysis to have a detailed profile of the thermal behaviour of the systems given the specified boundary conditions and evaluate the systems in terms of temperatures (primarily based on the 


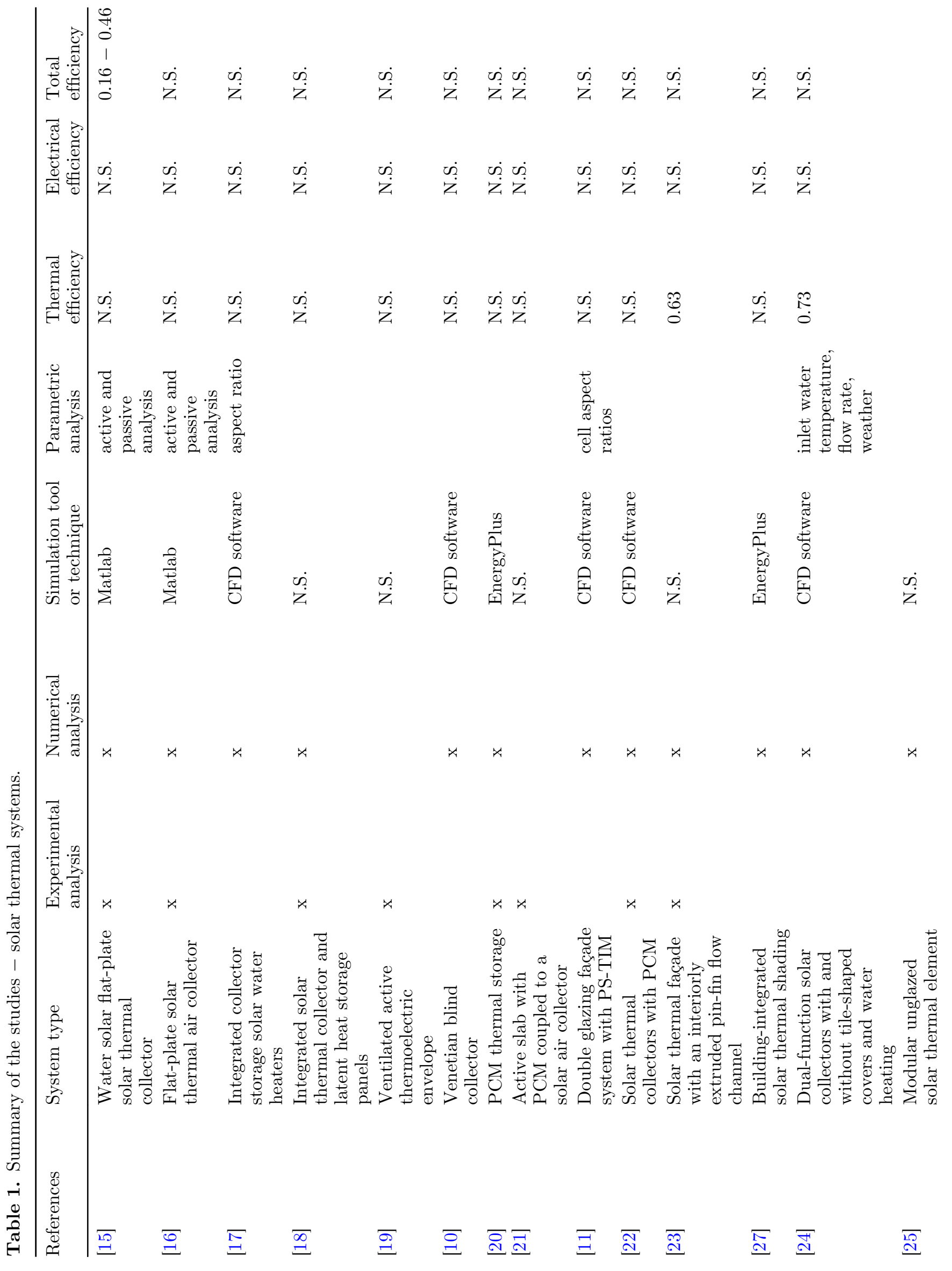




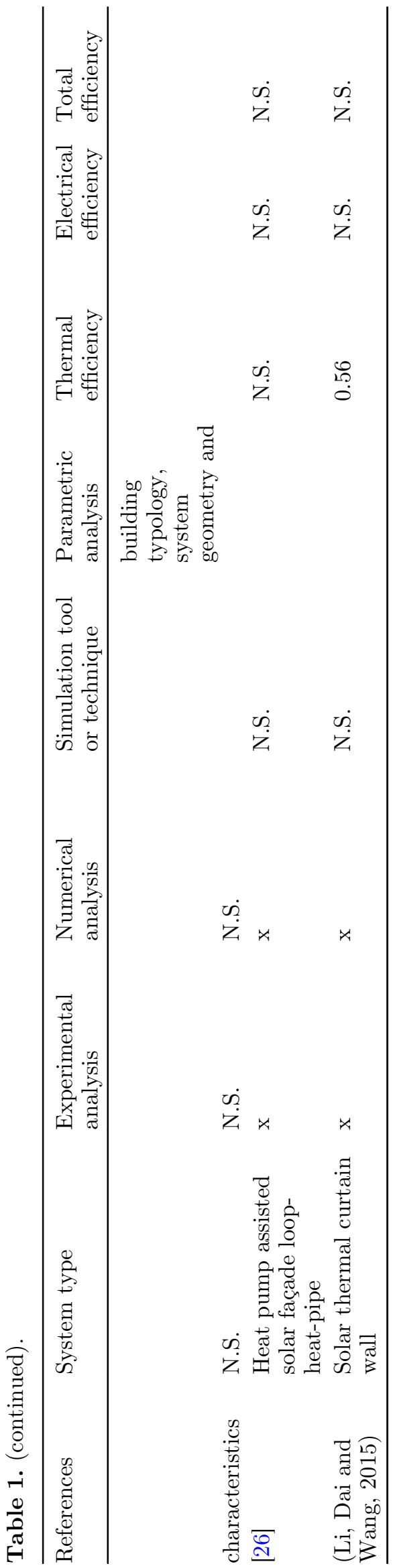

outlet-inlet differences). Parametric analysis is not always done in the reviewed studies. Still, in the studies that develop this component, the geometry, inlet velocity and inlet temperature $\left(T_{\text {inl }}\right)$ are the most used variables of variation.

\subsection{Integrated photovoltaic systems}

A sample of 37 scientific articles presented innovative solar photovoltaic systems (working only with the photovoltaic effect), among the 75 articles reviewed. A summary of the most pertinent is presented here, followed by a table summarising the studies. In Shukla et al. [28], an extensive review is given concerning the design of Building Integrated Photovoltaic (BIPV) systems. It focuses on developing the technology, classification of cells and products, and industry/research opportunities. Another study, developed by Tripathy et al. [29], presents a review of the state-of-the-art PV products for building different components of envelopes, their properties and their accordance with international standards.

In Aguacil et al. [30], the work aims to provide a methodology to contribute to the decision-making process concerning the use of BIPV in the urban renewal process. It considers the surface types and trade-offs between selfconsumption and self-sufficiency. It is a straightforward approach that aims to facilitate the analysis of suitability concerning different factors. Chen et al. [31] explored the impact of archetypes and confounding factors in optimising the design. They focus specifically on high-rise buildings with BIPV façades, using data-driven models incorporating qualitative and quantitative analysis. It intends to facilitate the analysis by defining typical types of façades in which the buildings In Biyik et al. [32], the authors reviewed the BIPV and BIPVT possible uses in terms of types, supply, generation power, performance characterization, and approaches of analysis. They identify two crucial research areas concerning this subject: (i) increase in system efficiency utilizing ventilation while reducing the modules temperature; (ii) use of thin-film applicable for integration in buildings. This study is an excellent source to assess the comparison between BIPVT and BIPVT. In Shukla et al. [33], the study also presents a comprehensive review of the BIPV commercial solutions and their characteristics and a comparison of international testing and operation standards and instructions. The authors focus on BIPV solutions for different façade elements.

In Agathokleous and Kalogirou [34], the authors study a naturally ventilated BIPV system, and the assessment is based on experimental thermal analysis. This study is particularly attractive, and further results obtained by the authors are presented in Table 2. In Agathokleous et al. [16], the authors continued the previous work by introducing a simulation-based thermal analysis of the same system. In Wang et al. [45], a ventilated PV doubleskin façade and a PV insulating glass unit are studied through comparative experiments to evaluate the systems' solar heat gain and U-value. In Cipriano et al. [54], the focus was on a PV ventilated component and a data-driven approach to iteratively identify the unknown parameters, determine their impact in the simulation outputs and 
ultimately, assess the deviations of the computational outcomes against the measured data. In Peng et al. [56], the authors used EnergyPlus and developed a whole-year energy performance evaluation and saving potential of a ventilated photovoltaic double-skin façade in a coolsummer Mediterranean climate zone. The work developed a sensitivity analysis over the numerical model, considering different air gap width and operation models of the ventilation. In Pantic et al. [57], they present a theorybased and experimental investigation of electricity generation potential concerning different orientations of the modules in the façade elements.

In Asfour [37], the study focuses on the association of the PV modules in shading devices, and the investigation is oriented to hot climates. They also develop a parametric simulation to evaluate the potential of different designs. In Luo et al. [60], PV-blind embedded double skin façade is studied by coupling thermal-electrical-optical models. The aim was to evaluate and optimize the system by using raytracing, radiosity and net radiation methods, and other usual thermal models for buildings. In Tablada et al. [40], the authors also study the use of PV coupled to shading devices for farming plants growing application - focusing on windows and balconies. In [35], the study derived a new metric for assessing the daylight quality by comparing different coverage ratios of the PV cell and window-wall ratios. They also compared different orientations and estimated the net electricity use of the building. Karthick et al. [42], they investigated semi-transparent building integrated photovoltaic modules on façades, focusing on different coverage ratios. In Zhang et al. [43], the authors also explore the potential savings generated by the use of PV associated with shading elements, developing a parametric analysis concerning tilt angles and orientation of the system.

In Connelly et al. [48], the idea of semi-transparent BIPV with concentrator is additionally investigated. They propose a "smart window" framework comprising a thermotropic layer with integrated PV modules. The authors propose a system that naturally reacts to climatic conditions and analyse the power generation, natural light availability and heat transfer from the system to the building structure through parametric analysis of different solar energy ratios incident on the PV. In Wang et al. [49], they evaluated the energy performance of an a-Si semi-transparent PV insulating glass unit via numerical simulation and experimental tests. Considering the measured optical and electrical features of the PV, an integrated model was made to simulate the system's energy performance under analysis. In Favoino et al. [50], they propose a novel simulation framework for the performance evaluation of a responsive structure based on envelope advances in the switchable photochromatic coating. The analysis is done by incorporating building energy simulation and lighting simulation and varying parameters as the climate in which it is inserted.

In Wu et al. [52], a novel static concentrating PV system, reasonable for use in windows or coating exteriors, has been proposed. The proposed concentrating PV system is lightweight, with minimal economic effort and ready to produce power. Moreover, this system consequently reacts to atmospheric conditions by changing the parity of power created by the PV with the measure of sunlight-based light and heat allowed through it into the structure. It also offers the possibility to control the energy utilization in the building. Liu et al. [58], improved the structure of a commonplace semitransparent PV module and investigated the utilization of three sorts of high-reflectivity heat protection movies to frame the BIPV. Hence, the creators broke down the impact of the system structures on the optical, heat, and control time execution of the semitransparent PV module and how much the execution improved.

Qiu et al. [36] investigate mergers of vacuum glazing and BIPV integration and analyse its capacity to reduce the energy needs of the buildings. Huang et al. [38] also present a detailed investigation of a similar novel system's thermal and power efficiencies, a combined design improvement of photovoltaic envelope solutions. In Sun et al. [48], they combine optical, electrical and energy models to assess the integration of semi-transparent photovoltaic in commercial buildings. The publication assesses the effect of window design on the energy needs of the building. In Tak et al. [44], the authors structured a semi-transparent sun-powered cell window, in which the transparency can be changed by modifying its temperature and dissolvable vapour pressure. Further details may be seen in the reference. A modelling test with the proposed system was led to look at the impacts on energy utilization, power generation, and inhabitant comfort. The outcomes demonstrate that the proposed window has a significant potential to generate electrical energy.

In Sornek et al. [41], a Fresnel lens is used to increase the efficiency of BIPV systems. The analysis of the system is made both employing dynamic simulations and experimental campaigns. They improved the general productivity of the building integrated photovoltaic systems by the use of a Fresnel lens. During the tests, the efficiency of the photovoltaic module increased by about $7 \%$ (reaching an $\eta_{e}$ of $22 \%$ ). In Bunthof et al. [47], they build up the examination dependent on three Concentrator Photovoltaic (CPV) systems arrangements that consider the development of semi-straightforward structure veneer components. The systems likewise are a Fresnel focal point based concentrator and a novel level planar optic concentrator. In Correia et al. [51], Luminescent Solar Concentrators are displayed as financially savvy parts effectively incorporated in PV that can improve and advance the integration between PV components and building structures, with considerable potential outcomes for energy generation in façades, while improving urban aesthetics. In Sabry [53], a range of prismatic total interior reflection low concentration PV façades with different head angles has been evaluated, dependent on the location and characteristics of the surrounding areas of the building. Every veneer design is mimicked by ray-tracing procedure. Its presentation is examined against sensible direct sun-based radiation information in two clear sky days representing the summer and winter of the area under study. Ray-tracing recreations uncovered that most of the chosen arrangements could gather the vast majority of the direct solar radiation in summer.

Kang et al. [59] developed a light-catching system connected to BI-SES based on the PV use, which naturally promotes light exposure during the entire year. The structure is streamlined for the precise scope of the 
occurrence light by breaking the underlying symmetry. The authors show the viability of the designed lightcatching structure for different occurrence point ranges employing exhaustive reproduction studies and trial results utilizing organic photovoltaic elements. In Hofer et al. [55], they present a modelling framework, coupling parametric 3D with high-resolution electrical modelling of the shading devices composed by thin-film PV modules, to reenact electric energy of geometrically complex PV applications. The proposed modelling framework can foresee with high spatial-transient resolution the shading positioning and adapt it over each PV module, being critical to improving the electricity generation through the adequate positioning of the modules and contributing to the control of direct solar gains in the building.

In Palacios-Jaimes et al. [46], a plan to transform a university building into NZEB is presented. It demonstrates that the BIPV system may provide the power needs and lessen the structure's energy use in a financially savvy way. The investigation emphatically centres around the life cycle assessment, surveying the net emissions of $\mathrm{CO}_{2}$ and the harms caused in a near setting with traditional power sources. In Yang [61], they identify the technical barriers and risks related to the utilization of BIPV in different building life-cycle stages, together with the proposal of potential arrangements. When a straightforward answer could not be proposed, suggestions for future innovative work are made. The proposed approach incorporates assessment of past productions and gathering of criticism from the business experts.

Table 2 presents the complete list and classification of the solar photovoltaic systems reviewed in this work, considering the system type, existence/non-existence of experimental and numerical analysis, existence/non-existence of parametrical analysis and details, reached efficiency of the system under study.

The results of this sub-section show a considerable amount of studies being made concerning BI-SES based on photovoltaic technology. Based on this review, three main design trends were identified: (i) improvement of standard BIPV configurations through smart ventilation; (ii) use of photovoltaic technology integrated into building façades as shading devices; and (iii) use of concentrators in the PV systems integrated into building façades and rooftop. As in the previous category, many studies do not approach the systems in direct terms of efficiency (in this case, $\eta_{e}$ ). They are approached in terms of nominal energy needs, energy balances (demand and on-site supply), and system temperatures. Also, a parametric analysis is done mainly by varying parameters as orientation, cell coverage ratio, air gap width, ventilation rates, and geometries.

\section{3 (Building) integrated hybrid systems}

Compared with solar thermal collectors and photovoltaic systems, the integrated hybrid systems employ both technologies in the same system, generating both thermal energy and electricity. A sample of 22 scientific articles was considered as presenting coupled innovative solar photovoltaic and thermal systems, among the 75 are reviewed.
A summary of the most pertinent is presented here, followed by a table summarising the studies.

In Lee et al. [62], an extensive review is presented on $\mathrm{PV} / \mathrm{T}$ systems, being of particular interest to works concerning the design of innovative energy façade elements due to the novelty of the strategies presented. The study reviews the structure guidelines and working instruments of the $\mathrm{PV} / \mathrm{T}$ façade systems, execution, control procedures and building applications. They highlight the use of electrochromic coating as the most used smart coating for thermal applications in PV systems and also stress that concerning PV shading, the external shading is the most utilized due to its low initial costs. The authors also state that algae growth façades and folding façades (complex geometry) shading systems are rising solutions, with high initial investment costs and requiring professional installers. They are, indeed, a promising arrangement because of their multi-purpose capabilities. Dynamic shading systems were found to spare $12 \%$ to $50 \%$ of the structure cooling power utilization. In Lai and Hokoi [63], a survey of a significant number of shading systems on the main façades facing south or north (depending on the hemisphere, referred to as sun-oriented façades) is presented, considering studies that have been published after 2010, segmenting the study in opaque and translucid elements.

In a most recent study by Lai and Hokoi [64], the state of the art sun-oriented control systems for façades are introduced, with a comparative assessment of sun-powered control systems and guidelines for improving new ones. It incorporates multifunctional frameworks and modelling with BIPV and thermal energy generation. In complement, in Debbarma et al. [65], the authors survey the BIPV and BIPVT advancements and energy, and the exergy examination of BIPV and BIPVT systems are likewise discussed. This work reviews the ongoing betterment of innovation around the world. In Agathokleous and Kalogirou [66], the work presents state of the art on thermal analysis of double skin façades with BIPV in terms of the published studies on these systems. In Zhang et al. [67], an in-depth review of the recently emerging active building-integrated solar thermal/PV technologies is also provided. The authors elaborate on the concept, parameters of classification and assessment, among other topics.

In Nagy et al. [68], they propose a modular adaptive solar façade to couple the element with the very dynamic environment surrounding the building boundaries. The energy behaviour and aesthetic expression of the façade can be managed to employ high Spatio-temporal resolution responses. The design process and operational plan are described, along with simulation results of the thermal behaviour and power production/consumption. In Peng et al. [69], the authors elaborate on the energy performance of a ventilated photovoltaic façade under varied ventilation modes and controlling modes for different climacteric conditions, aiming to improve the energy conversion efficiency.

In Chialastri and Isaacson [70], a prototype of a BIPVT was constructed based on thermal and electrical energy, aiming to achieve visual comfort and shading control through the system application. In this article, the prototype was evaluated under various conditions to 


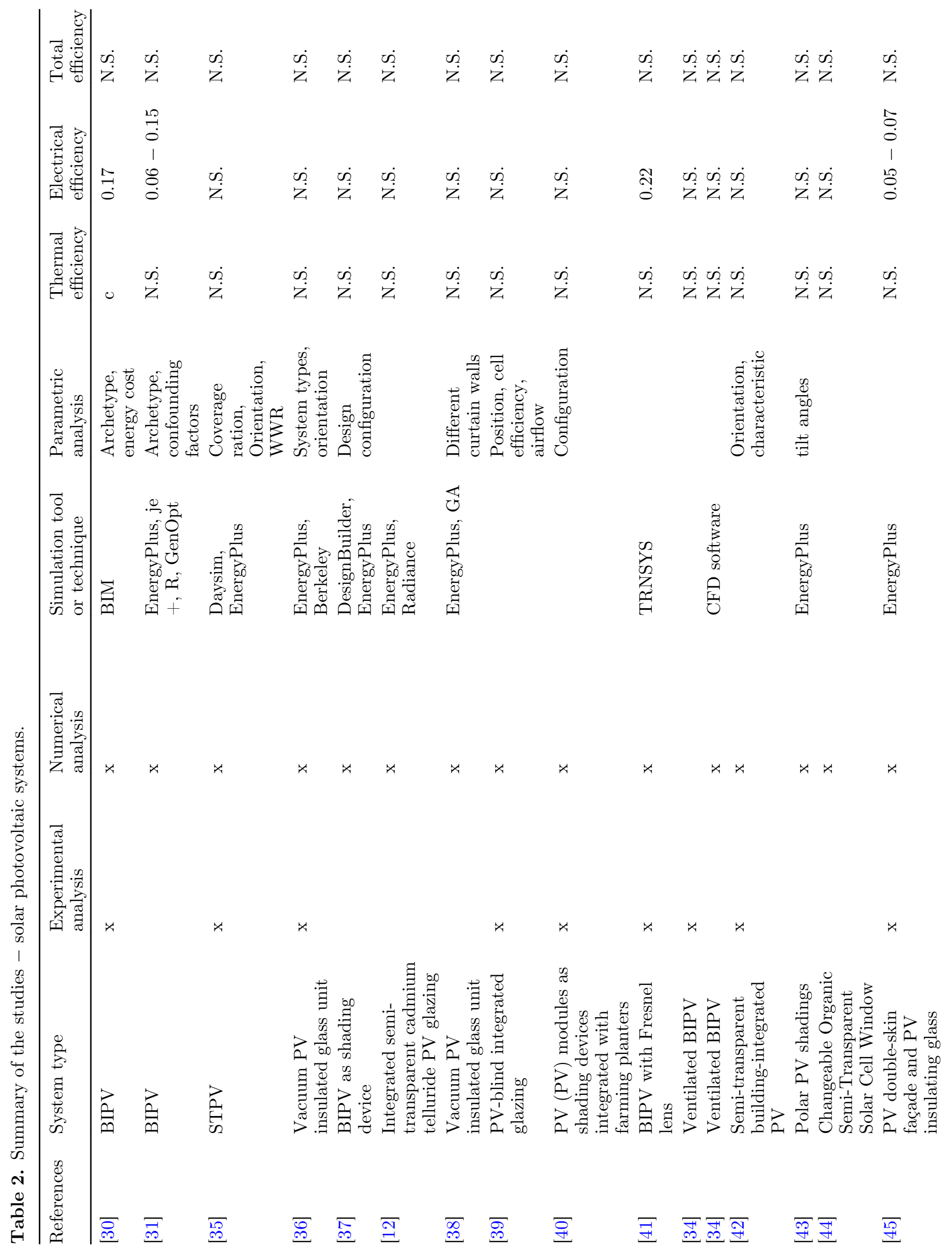




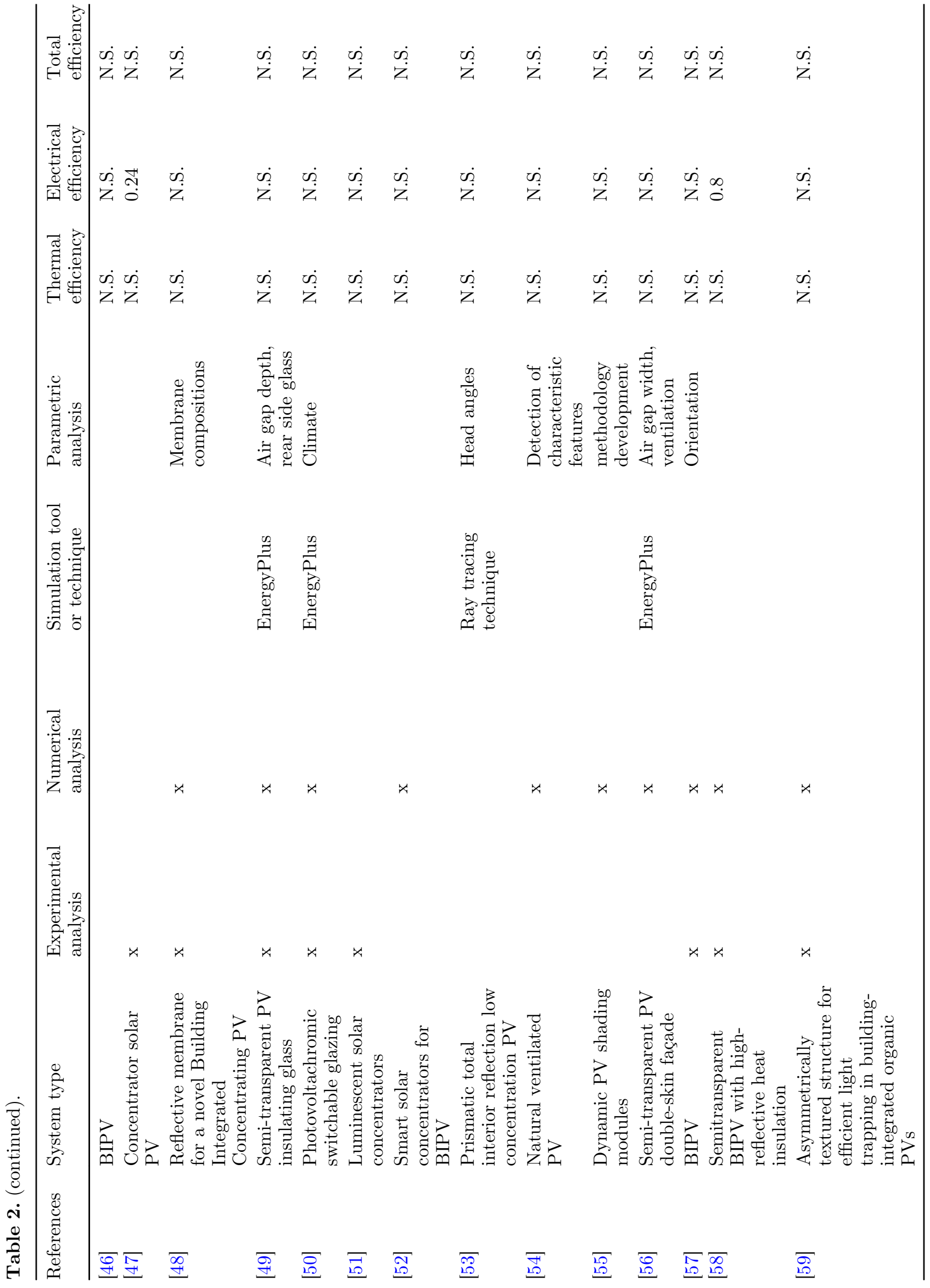


characterize its performance. Dehra [71] presents a study on energy evaluation of a photovoltaic wall using either natural convection incited or fan-helped ventilation system. The vertical photovoltaic sun-oriented wall was introduced on the façade of a pre-assembled outside test room. The prototype was developed with two economically accessible photovoltaic modules, an air cavity and an insulated back layer.

In Smyth et al. [72], the authors propose a modular hybrid photovoltaic/solar thermal façade technology that uses an Integrated collector storage solar technology. In light of a patented solar thermal diode concept and shaped into a flat modular profile incorporating PV cells/module, the proposed system aims to heat the indoor environment, provide hot water, and generate electricity. In Luo et al. [60], the authors proposed a building-integrated photovoltaic, thermoelectric wall solution. It is examined by a numerical model comprising a PV framework and thermoelectric brilliant wall element. The thermal and electrical components of the system under cooling prevailing atmospheres was numerically researched utilizing an iterative system model. The presentation of the system is optimized by a comparative investigation with a traditional solid wall.

In Barman et al. [73], the study investigates the outcomes of a solar transparent photovoltaic window, focusing on angles of incidence, thermal gains using direct solar gains and energy generation. In Ahmed-Dahmane et al. [74], the proposed BIPVT system prototype comprises air collectors connected to an air handling unit to manage the airflow. The solution works based on two applications, namely for heating and cooling needs.

In Gaur and Tiwari [75], a BIPVT system is analysed. There is a focus on improving the articulation between electrical and thermal efficiencies and heat transfer through the structure. These thermal and electrical efficiencies articulations are crucial for various climatic conditions and diverse façade BI-SES designs. The system modules have been intensely studied for their energy, exergy and operational attributes with and without associated air pipe. Buonomano et al. [76], a BIPVT system has been analysed for residential applications, assessing active and passive operational applications. In Oh et al. [77], they built up an incorporated model for evaluating the techno-financial execution of the BIPVT on façades, emphasising energy demand and supply. In $[78,79]$, the authors develop an experimental study of a Building-Integrated Photovoltaic system combined with a water storage tank prototype. The authors achieve a thermal efficiency of nearly $8 \%$ during the winter and $40 \%$ during the summer. In [80], a CFD study is presented for the prototype with an interior module of insulation instead of the water tank. This new modular prototype constituted a next step study of previous prototypes proposed by the research group, as may be consulted in [81,82]. Also to note is the work presented in [83], in which they assess a BIPVTPCM prototype via genetic algorithm optimization. Having as case study the same living lab in which these prototypes were tested, in [84] it is possible to find a numerical study of a full scale BIPVT system. In [85], the experimental results for this BIPVT system are presented.

Table 3 presents the complete list and classification of the hybrid solar systems reviewed in this work, considering the system type, existence/non-existence of experimental and numerical analysis, existence/non-existence of parametrical analysis and details, reached efficiency of the system under study.

The hybrid systems presented by the sample of publications reviewed in the scope of this work are, mainly, façade elements of BIPVT walls, in which the principal analysis is made through numerical simulation via a finite element of CFD analysis. Also, as in the previous sub-sections, many of the studies do not present the results in terms of system efficiency, and parametric analysis is developed in nearly half of them. The parameters under examination in the parametric analysis are ventilation nodes and velocity, geometry (duct width, for example) and glazing type.

\section{Conclusions}

This article intended to present a literature review to contribute to increasing knowledge and systematization of different building-integrated solar energy systems. The façades of the buildings offer huge potential to increase the sustainability of the built sector. Its association with building-integrated solar energy systems demonstrates that they can not only increase the comfort of the building and reduce the energy consumption but also respond to the necessities of the grid, especially concerning adaptive systems. A sample of 71 studies was reviewed in this study, and the results were segmented into three categories: thermal systems, photovoltaic systems, and hybrid systems integrated into the façades. When applicable, the studies were further classified regarding the type of study, the tool used, parametric analysis parameters, and performance.

Concerning the solar thermal systems, the results show that there is not a specific trend concerning the systems under study in the most recent publications. However, the focus can be given to the integration between passive and active techniques and the modularity and multiple purposes of the same element. The technologies vary from innovative system design to innovative methods of operation or material combination. The results concerning the photovoltaic systems presented three main design trends were identified based on this review: i) improvement of standard BIPV configurations through smart ventilation; ii) use of photovoltaic technology integrated into building façades as shading devices, and iii) use of concentrators in the PV systems integrated into building façades and rooftop. The hybrid systems presented by the sample of publications reviewed in the scope of this work are, mainly, façade elements of BIPVT walls, in which the principal analysis is made through numerical simulation via a finite element of CFD analysis. 


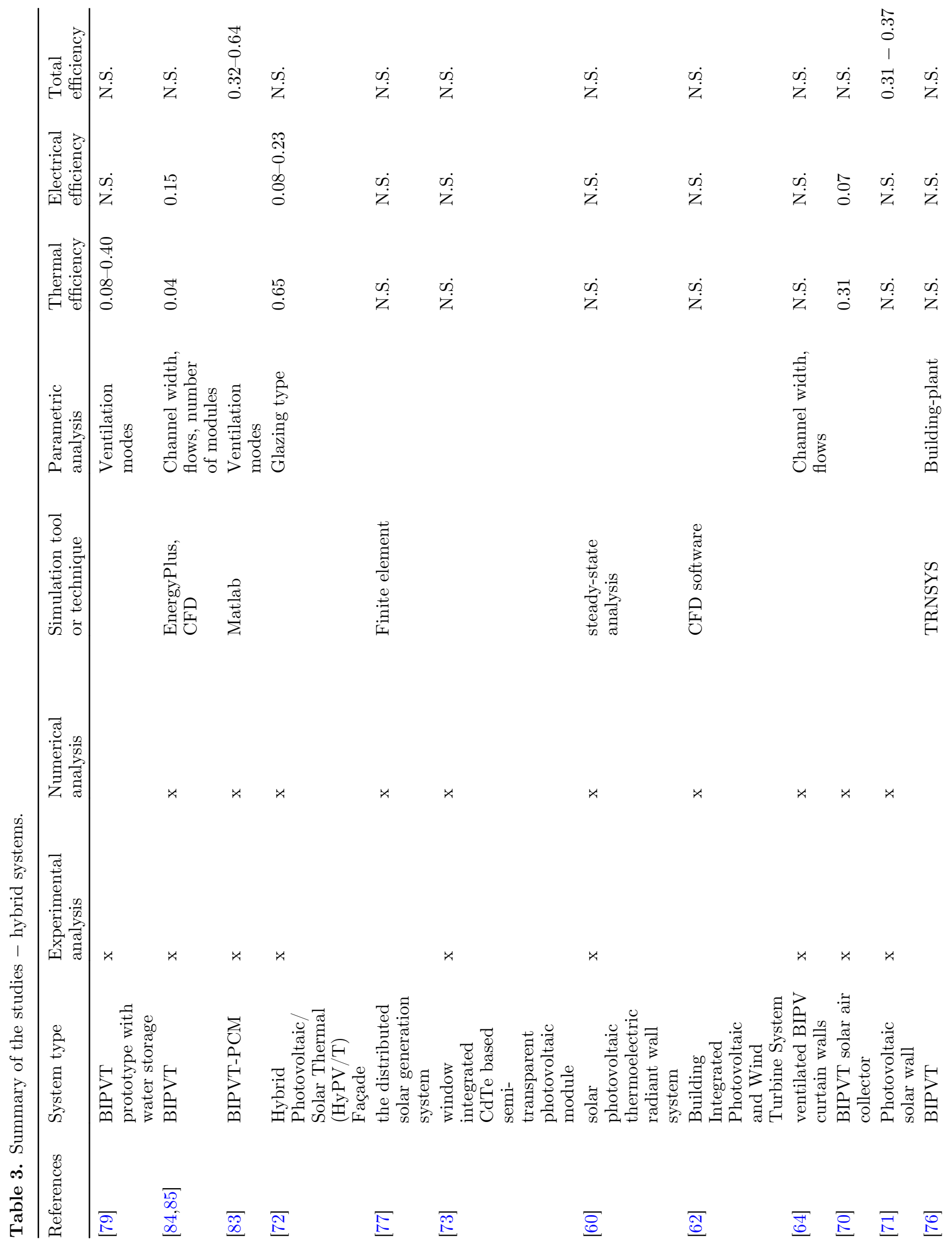




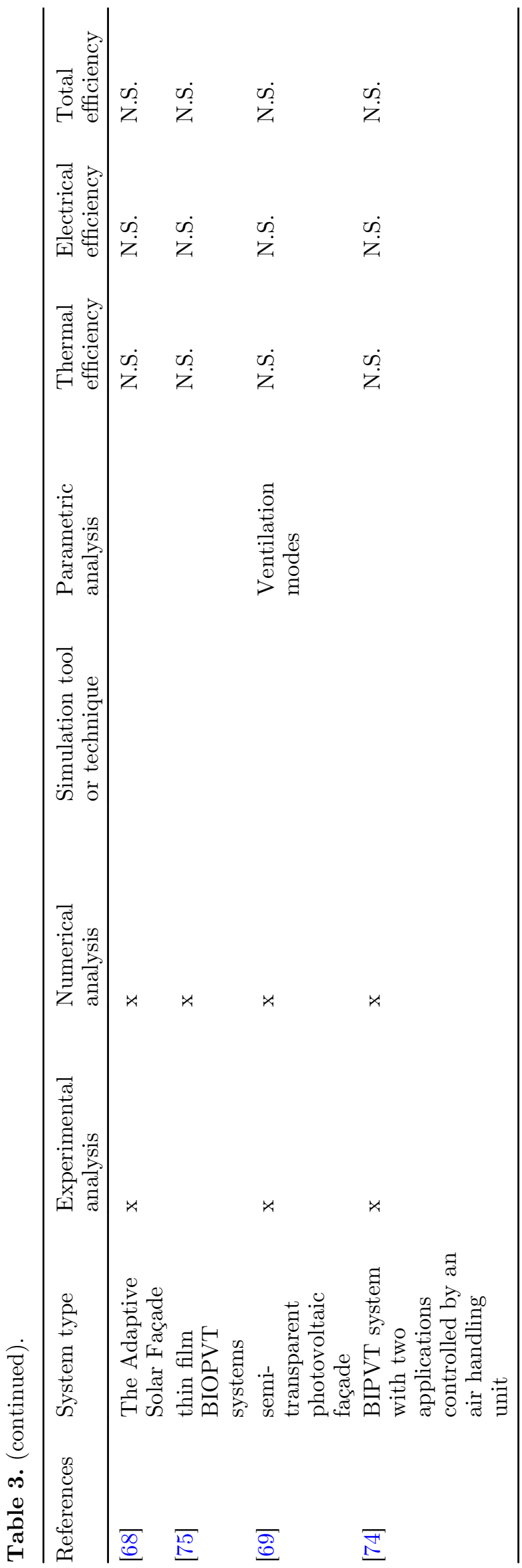

Acknowledgements. NZEB_LAB - Research Infrastructure on Integration of Solar Energy Systems in Buildings" (Ref. LISBOA01-0145-FEDER-022075)" is financed by national funds FCT/ MCTES (PIDDAC) and European FEDER from Regional Operation Program of Lisbon.

\section{References}

1. European Parliament 'Directive 2010/31/EU of the European Parliament and of the Council of 19 May 2010 on the energy performance of buildings (recast)' Official Journal of the European Union 2010; 2010

2. L. Aelenei, H. Petran et al., New challenge of the public buildings: nZEB findings from IEE RePublic_ZEB Project, Energy Proc. 78, 2016-2021 (2015)

3. L. Aelenei, S. Paduos et al., Implementing cost-optimal methodology in existing public buildings, Energy Proc. 78, 2022-2027 (2015)

4. M. Formentini, S. Lenci, An innovative building envelope (kinetic façade) with shape memory alloys used as actuators and sensors, Autom. Constr. 85, 220-231 (2018)

5. F. Pomponi et al., Energy performance of Double-Skin Façades in temperate climates: a systematic review and meta-analysis, Renew. Sustain. Energy Rev. 54, 1525-1536 (2016)

6. J. Borggaard et al., 'Control, estimation and optimization of energy efficient buildings, Proc. Am. Control Conf. 837-841 (2009)

7. A. Prieto et al., Feasibility study of self-sufficient solar cooling facade applications in different warm regions, Energies 11 (2018)

8. C. Maurer, C. Cappel, T.E. Kuhn, Progress in buildingintegrated solar thermal systems, Solar Energy 154, 158-186 (2017)

9. L.G. Valladares-Rendon, G. Schmid, S.-L. Lo, Review on energy savings by solar control techniques and optimal building orientation for the strategic placement of facade shading systems, Energy Build. 140, 458-479 (2019)

10. A. Velasco et al., Assessment of the use of venetian blinds as solar thermal collectors in double skin facades in mediterranean climates, Energies 10 (2017)

11. Y. Sun et al., Thermal evaluation of a double glazing facade system with integrated Parallel Slat Transparent Insulation Material (PS-TIM), Build. Environ. 105, 69-81 (2016)

12. Y. Sun et al., Integrated semi-transparent cadmium telluride photovoltaic glazing into windows: Energy and daylight performance for different architecture designs, Appl. Energy 231, 972-984 (2018)

13. R. O'Hegarty, O. Kinnane, S.J. McCormack, Review and analysis of solar thermal facades, Solar Energy 135, 408-422 (2016)

14. C. Lamnatou et al., Modelling and simulation of BuildingIntegrated solar thermal systems: behaviour of the system, Renew. Sustain. Energy Rev. 45, 36-51 (2015)

15. A. Buonomano et al., Building-façade integrated solar thermal collectors: energy-economic performance and indoor comfort simulation model of a water based prototype for heating, cooling, and DHW production, Renew. Energy (2018)

16. R. Agathokleous et al., Building facade integrated solar thermal collectors for air heating: experimentation, modelling and applications, Appl. Energy 239, 658-679 (2019) 
17. C. Garnier, T. Muneer, J. Currie, Numerical and empirical evaluation of a novel building integrated collector storage solar water heater, Renew. Energy 126, 281-295 (2018)

18. K. Resch-Fauster et al., Overheating protection of solar thermal facades with latent heat storages based on paraffinpolymer compounds, Energy Build. 169, 254-259 (2018)

19. M. Ibanez-Puy et al., Ventilated Active Thermoelectric Envelope (VATE): analysis of its energy performance when integrated in a building, Energy Build. 158, 1586-1592 (2018)

20. F. Guarino et al., PCM thermal storage design in buildings: Experimental studies and applications to solaria in cold climates, Appl. Energy 185, 95-106 (2017)

21. L. Navarro et al., Experimental study of an active slab with PCM coupled to a solar air collector for heating purposes, Energy Build. 128, 12-21 (2016)

22. F. Hengstberger et al., High temperature phase change materials for the overheating protection of facade integrated solar thermal collectors, Energy Build. 124, 1-6 (2016)

23. J. Shen et al., Characteristic study of a novel compact Solar Thermal Facade (STF) with internally extruded pin-fin flow channel for building integration, Appl. Energy 168, 48-64 (2016)

24. W. He et al., CFD and comparative study on the dual-function solar collectors with and without tile-shaped covers in water heating mode, Renew. Energy 86, 1205-1214 (2016)

25. A. Giovanardi et al., Integrated solar thermal facade system for building retrofit, Solar Energy 122, 1100-1116 (2015)

26. W. He et al., Operational performance of a novel heat pump assisted solar facade loop-heat-pipe water heating system, Appl. Energy 146, 371-382 (2015)

27. L. Li, M. Qu, S. Peng, Performance evaluation of building integrated solar thermal shading system: building energy consumption and daylight provision, Energy Build. 113, 189-201 (2016)

28. A.K. Shukla, K. Sudhakar, P. Baredar, A comprehensive review on design of building integrated photovoltaic system, Energy Build. 128, 99-110 (2016)

29. M. Tripathy, P.K. Sadhu, S.K. Panda, A critical review on building integrated photovoltaic products and their applications, Renew. Sustain. Energy Rev. 61, 451-465 (2016)

30. S. Aguacil, S. Lufkin, E. Rey, Active surfaces selection method for building-integrated photovoltaics (BIPV) in renovation projects based on self-consumption and selfsufficiency, Energy Build. 193, 15-28 (2019)

31. X. Chen, H. Yang, J. Peng, Energy optimization of high-rise commercial buildings integrated with photovoltaic facades in urban context, Energy 172, 1-17 (2019)

32. E. Biyik et al., A key review of building integrated photovoltaic (BIPV) systems, Eng. Sci. Technol. 20, 833858 (2017)

33. A.K. Shukla, K. Sudhakar, P. Baredar, Recent advancement in BIPV product technologies: a review, Energy Build. 140, 188-195 (2017)

34. R.A. Agathokleous, S.A. Kalogirou, Part II: thermal analysis of naturally ventilated BIPV system: modeling and simulation, Solar Energy 169, 682-691 (2018)

35. Y. Cheng et al., An optimal and comparison study on daylight and overall energy performance of double-glazed photovoltaics windows in cold region of China, Energy 170, 356-366 (2019)

36. C. Qiu, H. Yang, W. Zhang, Investigation on the energy performance of a novel semi-transparent BIPV system integrated with vacuum glazing, Build. Simul. 12, 29-39 (2019)
37. O.S. Asfour, Solar and shading potential of different configurations of building integrated photovoltaics used as shading devices considering hot climatic conditions, Sustainability 10 (2018) doi: 10.3390/su10124373

38. J. Huang et al., Numerical investigation of a novel vacuum photovoltaic curtain wall and integrated optimization of photovoltaic envelope systems, Appl. Energy 229, 1048-1060 (2018)

39. Y. Luo, L. Zhang, Z. Liu, X. Su et al., Coupled thermalelectrical-optical analysis of a photovoltaic-blind integrated glazing facade, Appl. Energy 228, 1870-1886 (2018)

40. A. Tablada et al., design optimization of productive facades: integrating photovoltaic and farming systems at the tropical technologies laboratory, Sustainability 10 (2018)

41. K. Sornek, M. Filipowicz, J. Jasek, The use of fresnel lenses to improve the efficiency of photovoltaic modules for buildingintegrated concentrating photovoltaic systems', J. Sustain. Dev. Energy Water Environ. Syst. 6, 415-426 (2018)

42. A. Karthick et al., Performance study of building integrated photovoltaic modules, Adv. Build. Energy Res. 12, 178-194 (2018)

43. W. Zhang, L. Lu, J. Peng, Evaluation of potential benefits of solar photovoltaic shadings in Hong Kong, Energy 137, 1152-1158 (2017)

44. S. Tak et al., 'Effect of the changeable organic semitransparent solar cell window on building energy efficiency and user comfort, Sustainability 9 (2017)

45. M. Wang et al., Comparison of energy performance between PV double skin facades and PV insulating glass units, Appl. Energy 194, 148-160 (2017)

46. G.Y. Palacios-Jaimes et al., Transformation of a University Lecture Hall in Valladolid (Spain) into a NZEB: LCA of a BIPV system integrated in its facade, Int. J. Photoenergy (2017) doi: 10.1155/2017/2478761

47. L.A.A. Bunthof et al., Impact of shading on a flat CPV system for facade integration, Solar Energy 140, 162-170 (2016)

48. K. Connelly et al., Design and development of a reflective membrane for a novel Building Integrated Concentrating Photovoltaic (BICPV) 'Smart Window' system', Appl. Energy 182, 331-339 (2016)

49. M. Wang et al., Assessment of energy performance of semitransparent PV insulating glass units using a validated simulation model, Energy 112, 538-548 (2016)

50. F. Favoino et al., Optimal control and performance of photovoltachromic switchable glazing for building integration in temperate climates, Appl. Energy 178, 943-961 (2016)

51. S.F.H. Correia et al., Scale up the collection area of luminescent solar concentrators towards metre-length flexible waveguiding photovoltaics, Progr. Photovolt. 24, 11781193 (2016)

52. Y. Wu et al., Smart solar concentrators for building integrated photovoltaic facades, Sol. Energy 133, 111-118 (2016)

53. M. Sabry, Prismatic TIR (total internal reflection) lowconcentration PV (photovoltaics)-integrated facade for low latitudes, Energy 107, 473-481 (2016)

54. J. Cipriano et al., Development of a dynamic model for natural ventilated photovoltaic components and of a data driven approach to validate and identify the model parameters, Solar Energy 129, 310-331 (2016)

55. J. Hofer et al., Parametric analysis and systems design of dynamic photovoltaic shading modules, Energy Sci. Eng. 4, 134-152 (2016) 
56. J. Peng et al., Numerical investigation of the energy saving potential of a semi-transparent photovoltaic double-skin facade in a cool-summer Mediterranean climate, Appl. Energy 165, 345-356 (2016)

57. L.S. Pantic et al., Electrical energy generation with differently oriented photovoltaic modules as facade elements, Thermal Sci. 20, 1377-1386 (2016)

58. H.-M. Liu et al., Improving the performance of a semitransparent bipv by using high-reflectivity heat insulation film, Int. J. Photoenergy (2016) doi: 10.1155/2016/4174216

59. J. Kang, C. Cho, J.-Y. Lee, Design of asymmetrically textured structure for efficient light trapping in buildingintegrated photovoltaics, Org. Electr. 26, 61-65 (2015)

60. Y. Luo, L. Zhang, Z. Liu, J. Wu et al., Numerical evaluation on energy saving potential of a solar photovoltaic thermoelectric radiant wall system in cooling dominant climates, Energy 142, 384-399 (2018)

61. R.J. Yang, Overcoming technical barriers and risks in the application of building integrated photovoltaics (BIPV): hardware and software strategies, Autom. Construct. 51, 92$102(2015)$

62. J. Lee et al., Renewable energy potential by the application of a building integrated photovoltaic and wind turbine system in global urban areas, Energies 10 (2017)

63. C.-M. Lai, S. Hokoi, Solar facades: a review, Build. Environ. 91, 152-165 (2015)

64. C. Lai, S. Hokoi, Experimental and numerical studies on the thermal performance of ventilated BIPV curtain walls, Indoor Built Environ. 26, 1243-1256 (2017)

65. M. Debbarma, K. Sudhakar, P. Baredar, Thermal modeling, exergy analysis, performance of BIPV and BIPVT: a review, Renew. Sustain. Energy Rev. 73, 1276-1288 (2015)

66. R.A. Agathokleous, S.A. Kalogirou, Double skin facades (DSF) and building integrated photovoltaics (BIPV): a review of configurations and heat transfer characteristics, Renew. Energy 89, 743-756 (2016)

67. X. Zhang et al., Active Solar Thermal Facades (ASTFs): From concept, application to research questions, Renew. Sustain. Energy Rev. 50, 32-63 (2015)

68. Z. Nagy et al., The adaptive solar facade: from concept to prototypes, Front. Architectur. Res. 5, 143-156 (2016)

69. J. Peng et al., Comparative study of the thermal and power performances of a semi-transparent photovoltaic facade under different ventilation modes, Appl. Energy 138, 572583 (2015)

70. A. Chialastri, M. Isaacson, Performance and optimization of a $\mathrm{BIPV} / \mathrm{T}$ solar air collector for building fenestration applications, Energy Build. 150, 200-210 (2017)

71. H. Dehra, An investigation on energy performance assessment of a photovoltaic solar wall under buoyancy-induced and fanassisted ventilation system, Appl. Energy 191, 55-74 (2017)
72. M. Smyth et al., Experimental performance characterisation of a hybrid photovoltaic/solar thermal facade module compared to a flat integrated collector storage solar water heater module, Renew. Energy 137, 137-143 (2019)

73. S. Barman et al., Assessment of the efficiency of window integrated CdTe based semi-transparent photovoltaic module', Sustain. Cities Soc. 37, 250-262 (2018)

74. M. Ahmed-Dahmane, A. Malek, T. Zitoun, Design and analysis of a BIPV/T system with two applications controlled by an air handling unit', Energy Convers. Manag. 175, 49-66 (2018)

75. A. Gaur, G.N. Tiwari, Analytical expressions for temperature dependent electrical efficiencies of thin film BIOPVT systems, Appl. Energy 146, 442-452 (2015)

76. A. Buonomano et al., BIPVT systems for residential applications: an energy and economic analysis for European climates, Appl. Energy 184, 1411-1431 (2016)

77. J. Oh et al., An integrated model for estimating the technoeconomic performance of the distributed solar generation system on building façades: focused on energy demand and supply, Appl. Energy 228, 1071-1090 (2018)

78. M.A.C. Sousa, L. Aelenei, H. Gonçalves, Comportamento térmico de um protótipo BIPV combinado com armazenamentode água: análise experimental, in CIES2020-XVII Congresso Ibérico e XIII Congresso Ibero-americano de Energia Solar. LNEG-Laboratório Nacional de Energia e Geologia (2020) 1167-1174

79. J.M. Lourenço et al., Thermal behavior of a BIPV combined with water storage: an experimental analysis, Energies 14, 2545 (2021)

80. K. Bot, L. Aelenei, H. Gonçalves, Design de um protótipo BIPVT e análise por meio de computação dinâmica de fluídos, in CIES2020-XVII Congresso Ibérico e XIII Congresso Ibero-americano de Energia Solar. LNEG-Laboratório Nacional de Energia e Geologia (2020) pp. 1185-1192

81. L. Aelenei, R. Pereira, A. Ferreira et al., Building Integrated Photovoltaic System with integral thermal storage: a case study, Energy Proc. 58, 172-178 (2014)

82. L. Aelenei, R. Pereira, H. Gonçalves et al., Thermal performance of a hybrid BIPV-PCM: modeling, design and experimental investigation, Energy Proc. 48, 474-483 (2014)

83. R. Pereira, L. Aelenei, Optimization assessment of the energy performance of a BIPV/T-PCM system using genetic algorithms, Renew. Energy (2018)

84. K. Bot et al., Performance assessment of a building integrated photovoltaic thermal system in mediterranean climate - a numerical simulation approach', Energies 13 (2020)

85. K. Bot et al., Performance assessment of a buildingintegrated photovoltaic thermal system in a mediterranean climate - an experimental analysis approach, Energies 14, $2191(2021)$

Cite this article as: Karol Bot, Laura Aelenei, Maria da Glória Gomes, Carlos Santos Silva, A literature review on Building Integrated Solar Energy Systems (BI-SES) for façades - photovoltaic, thermal and hybrid systems, Renew. Energy Environ. Sustain. 7, 7 (2022) 